\title{
Method for Productive Cattle Finding with Estrus Cycle Estimated with BCS and Parity Number and Hormone Treatments based on a Regressive Analysis
}

\author{
Kohei Arai, Narumi Suzaki, Iqbal \\ Ahmed, Osamu Fukuda, Hiroshi \\ Okumura \\ Graduate School of Science and \\ Engineering \\ Saga University \\ Saga City, Japan
}

\author{
Kenji Endo \\ Morinaga Dairy Service Co. Ltd. \\ 1-159 Toyoharaotsu, Nasugun \\ Nasumachi, \\ Tochigi 329-3224, Japan
}

\author{
Kenichi Yamashita \\ The National Institute of Advanced \\ Industrial Science and Technology \\ (AIST), 807-1 Shuku-machi, Tosu \\ Saga 841-0052, Japan
}

\begin{abstract}
Estrus cycle estimation method through correlation analysis among influencing factors based on regressive analysis is carried out for Japanese Dairy Cattle Productivity Analysis. Through the experiments with 280 Japanese anestrus Holstein dairy cows, it is found that estrus cycle can be estimated with the measured with visual index of Body Condition Score (BCS), hormone treatments, and parity number, based on regressive equation. Also, it is found that the time from the delivery to the next estrus can be expressed with BCS, hormonal treatments, parity. Thus it is found that productivity of cattle can be identified.
\end{abstract}

Keywords-Body Condition Score (BCS); postpartum interval; parity number; estrous cycle; cattle productivity

\section{INTRODUCTION}

Productivity of daily cattle is getting down now-a-days due to the fact that estrus cycle is getting longer and longer. The typical estrus cycle is around 21 days [1]-[4]. In order to improve the productivity, it would be better to find productive cattle which have a relatively short estrus cycle. Therefore, there has been proposed methods for productive cattle finding [5]-[12].

It is better to find productive cattle by using visual perception, such as Body Condition Score (BCS), and so on because it is easy to measure. On the other hand, hormone treatments are useful to productivity of cattle.

BCS, days after childbirth and or postpartum interval (PPI), parity number, ovarian characteristics, uterine blood flow, progesterone level (P4), climate and nutritional factors which are mostly discovered by influential factors in this arena [13][16]. Meanwhile, estrous synchronization protocol assists to get higher pregnancy rate in many countries [17]. On the other hand, ultrasound image analysis is very useful to find pregnancy level [18]-[22].

The most influential factors against productivity of cattle is BCS [13], [23], [24]. The authors have proposed the method for estrus cycle estimation with three influential factors (BCS, postpartum interval, and parity) for understanding the presence and absence of estrous cycle using a new unique Bayesian Network Model (BNM) [25]. It, however, is not possible to consider relations among the influencing factors. Joint probability among the influencing factors cannot be taken into account.

In this paper, regressive analysis based method for estrus cycle estimation is proposed here in this paper in order to consider a relation among the influencing factors. Experiments are conducted with 280 different Japanese Holstein cows observing with their BCS (2.0 to 3.25), hormonal treatments and parity numbers in order to discover the ideal timing for artificial insemination to make them pregnant. It is also important to mention that, all these 280 samples found anestrus in their farm. The experimental results are compared to the previous method of BNM. It is clear from National Livestock Breeding Center (NLBC), Japan that the overall conception rate of live beef and dairy cattle is decreasing in last 20 years in Japan [26]. Moreover, the findings of relations among influencing factors of the measured BCS, hormone treatments, parity number, and so on are other objectives for improving cattle productivity and herd management.

The next section describes research background followed by preliminary analysis and experiment. Then experimental results are compared to the results from the Bayesian Network approach followed by concluding remarks and future work.

\section{RESEARCH BACKGROUND}

There are the following influencing factors for estimation of estrus cycle, BCS, PN, CIDR, and PG.

\section{A. Body Condition Scoring}

Fig. 1 shows examples of the different BCS of the cows whose BCS of 3, 2.75, 2.5, and 2.25 are from the left to the right, respectively. As shown in Fig. 1, BCS indicates fatty level of daily cattle. BCS and its general meaning for 280 sample daily cattle provided by the Morinaga Dairy Service (MDS) Co. Ltd., Japan is shown in Table 1. 


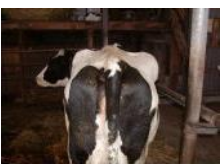

(a) $\mathrm{BCS}=3$

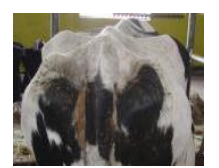

(b) $\mathrm{BCS}=2.75$

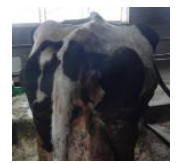

(c) $\mathrm{BCS}=2.5$

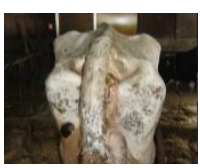

(d) $\mathrm{BCS}=2.25$
Fig. 1. Examples of the back view of the different BCS cows.

TABLE. I. BCS AND ITS GENERAL MEANING FOR 280 SAMPLE Cows

\begin{tabular}{|l|l|}
\hline BCS & Meaning (in general) \\
\hline 2.25 & No fat pads on pin and hook bones- angular shape \\
\hline 2.5 & Palpable fat pads on pin and hook bones- angular shape \\
\hline 2.75 & $\begin{array}{l}\text { Pin bones- round shape and hook bones- angular shape } \\
\text { with less fat pads }\end{array}$ \\
\hline 3.0 & Fat pads on pin and hook bones- round shape \\
\hline 3.25 & Visible fat pads on pin and hook bones- round shape \\
\hline
\end{tabular}

B. Parity Number/Number of Calves

The number of delivery of baby cattle is defined as Parity Number (PN). In this paper, PN of the 280 of Holstein of daily cattle ranges from 1 to 9 .

\section{Hormone Treatments}

Hormone treatments can be divided into two categories: CIDR and PG.

1) CIDR

- Vaginal indwelling type luteinizing hormone preparation.

- Prepare estrus.

2) $\mathrm{PG}$

- Prostaglandin.

- Uterine empyema.

Usually, CIDR is applied to the cattle has no estrus for a long time for prompt estrus. If the CIDR does not work, then PG is applied to the cattle.

\section{PRELIMINARY ANALYSIS}

BCS were observed in accordance with the UV method of Ferguson [24] by an experienced animal scientist of MDS Co. Ltd. These 280 individual cattle were Japanese Holstein breed, which were found anestrus in the farm in Iwate Prefecture, Japan. The overall investigation for all these problematic dairy cows is under observation of MDS Co. Ltd.

Single regressive analysis is conducted for investigation of the following relations:

1) Estrus cycle and BCS

2) Estrus cycle and uterine empyema

3) Estrus cycle and ovarian disorder

4) Estrus cycle and CIDR

5) Estrus cycle and PG.
Fig. 2(a) to (e) shows the results from the single regressive analysis for 280 of cattle. There are five categories for BCS ranges from 2.25 to 3.25 . BCS $=2.5$ of cattle shows the highest percentage ratio of estrus followed by $\mathrm{BCS}=2.75, \mathrm{BCS}=3$, $\mathrm{BCS}=2.25$ and $\mathrm{BCS}=3.25$. Therefore, 2.5 to 2.75 of $\mathrm{BCS}$ is appropriate shape of cattle. On the other hand, fatty and slender shape of cattle is not appropriate for estrus.

There are two major reproductive dysfunctions, uterine empyema and ovarian disorder. Once reproductive dysfunction is onset for the specific cattle, then the estrus cycle of the cattle is disappeared. Even if there is no reproductive dysfunction, it is not always true that estrus cycle is appeared for the cattle. The percentage ratio of the former case is $64 \%$ while that of the latter case is $36 \%$ for the reproductive dysfunction due to uterine empyema as shown in Fig. 2(b). That is almost same thing for ovarian disorder. Namely, the percentage ratio of the former case is $64 \%$ while that of the latter case is $36 \%$ for the reproductive dysfunction due to ovarian disorder as shown in Fig. 2(c).

On the other hand, there are two hormonal treatments, CIDR and PG. As shown in Fig. 2(d) and (e), around 55\% of cattle have estrus cycle. A portion of the rest of $45 \%$ cattle have estrus cycle when they had a hormonal treatment, CIDR or PG. Usually, the cattle which need a hormonal treatment have CIDR then PG when CIDR does not work for the cattle.

One of the indicators of the single regressive analysis of $\mathrm{P}$ values of the single regressive analysis is shown in Table 2 . $\mathrm{P}$ value of $\mathrm{BCS}$ is so nice that $\mathrm{BCS}$ is excellent indicator for estrus cycle followed by reproductive dysfunction and CIDR, and PG as shown in Table 2.

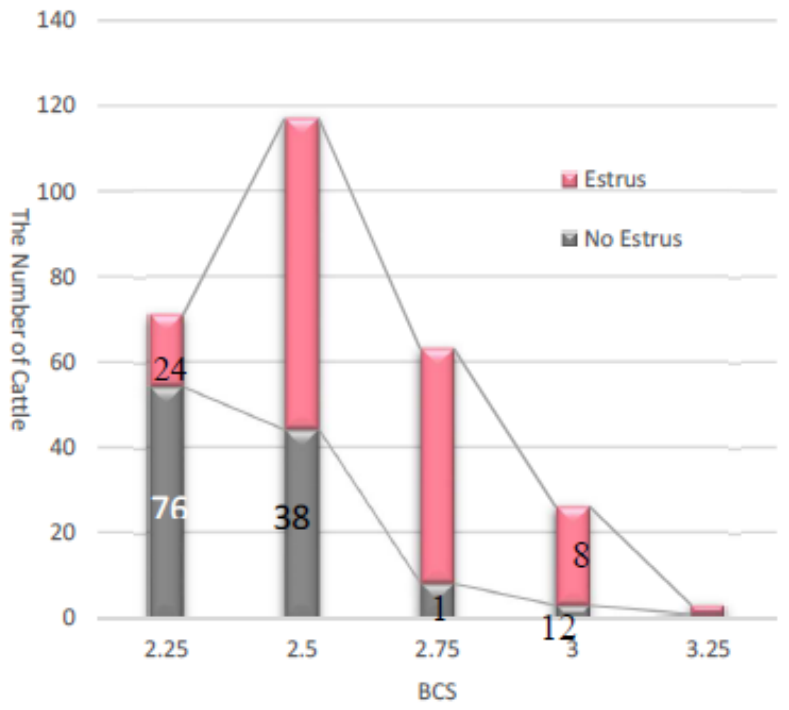

(a) BCS 


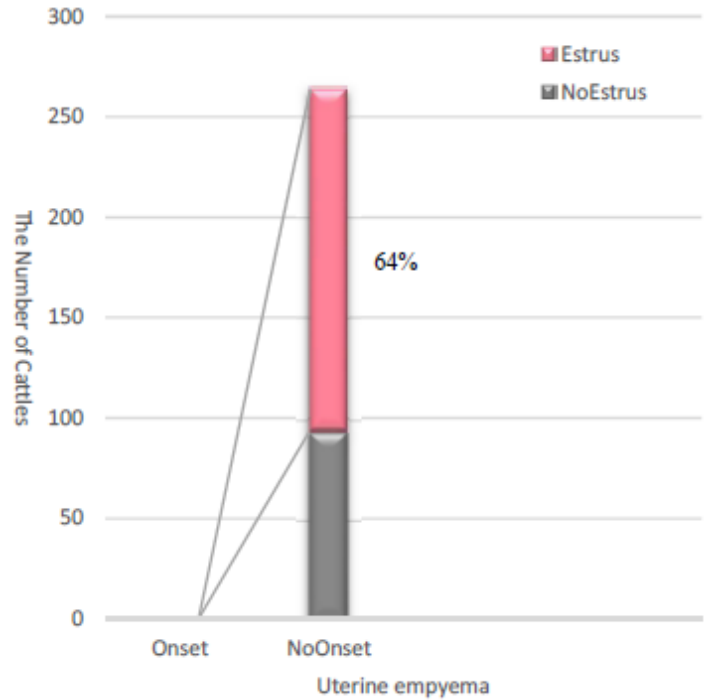

(b) Uterine empyema

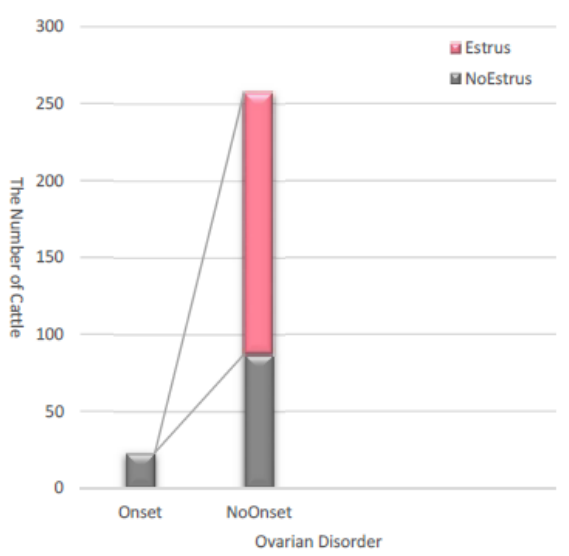

(c) Ovarian disorder

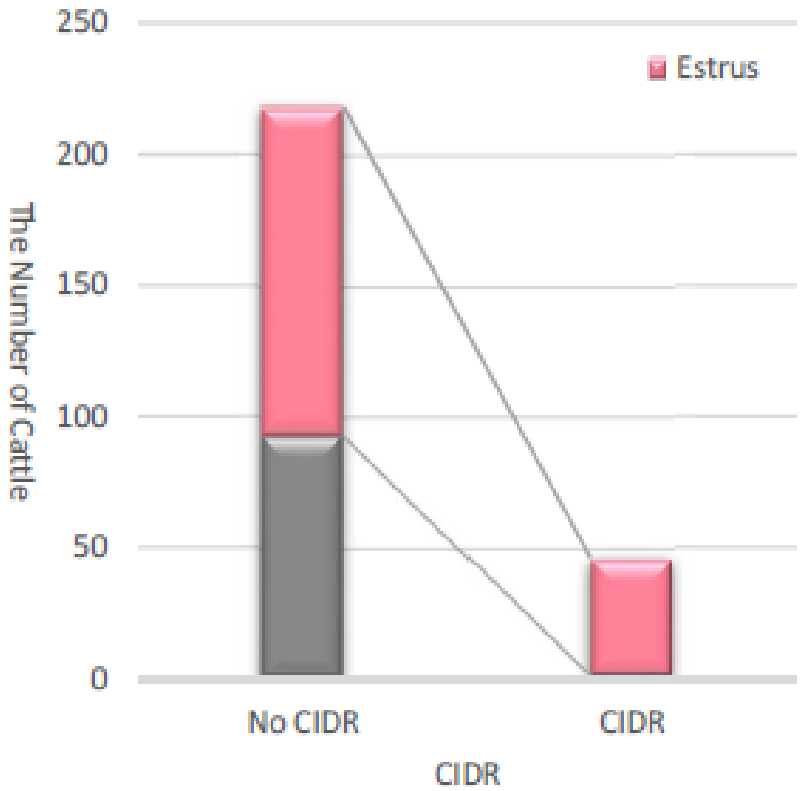

(d) CIDR

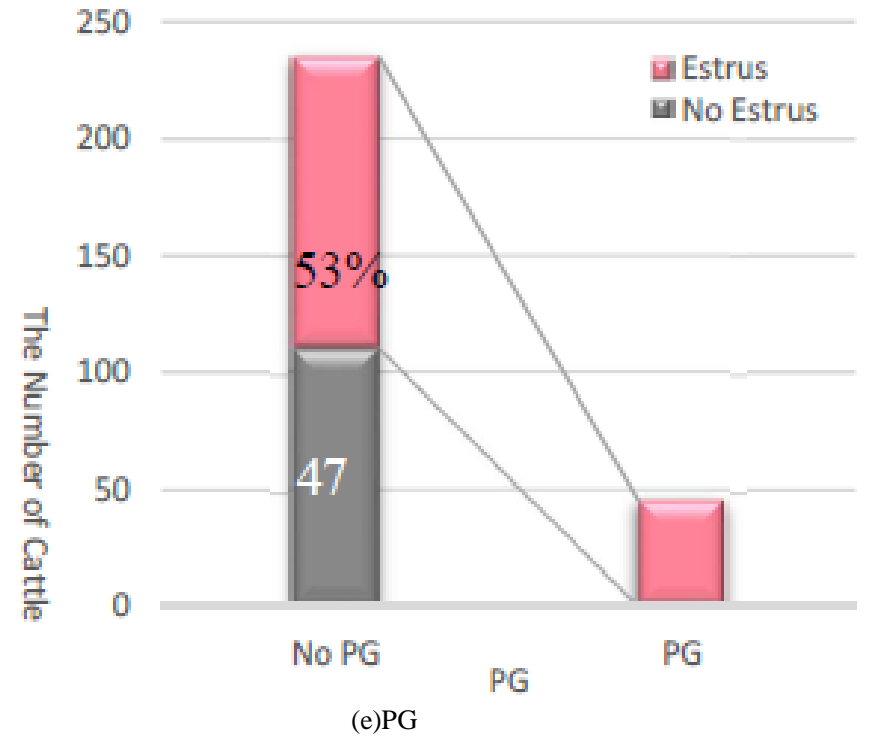

Fig. 2. (a)-(e): Results from the single regressive analysis for 280 of cattle.

TABLE. II. P VALUES OF THE SINGLE REGRESSIVE ANALYSIS a) $\mathrm{BCS}$

\begin{tabular}{|c|c|}
\hline & P Value \\
\hline Cross section & $4.6817 \times 10^{\wedge}-9$ \\
\hline BCS & $6.8000 \times 10^{\wedge}-16$ \\
\hline \multicolumn{2}{|c|}{ (b) Uterine empyema } \\
\hline \multicolumn{2}{|c|}{ P Value } \\
\hline Cross section & $2.7294 \times 10^{\wedge}-2$ \\
\hline Uterine empyema & $1.800 \times 10^{\wedge}-9$ \\
\hline
\end{tabular}

\begin{tabular}{|c|c|}
\hline \multicolumn{2}{|c|}{ (c) Ovarian disorder } \\
\hline Cross section & P Value \\
\hline Ovarian disorder & $2.4040 \times 10^{\wedge}-3$ \\
\hline
\end{tabular}

\begin{tabular}{|c|c|}
\hline \multicolumn{2}{|c|}{ (d) CIDR } \\
\hline & P Value \\
\hline Cross section & $1.707 \times 10^{\wedge}-2$ \\
\hline CIDR & $7.400 \times 10^{\wedge}-9$ \\
\hline
\end{tabular}

(e) PG

\begin{tabular}{|c|c|}
\hline & P Value \\
\hline Cross section & $6.4348 \times 10^{\wedge}-2$ \\
\hline PG & $3.038 \times 10^{\wedge}-6$ \\
\hline
\end{tabular}

\section{EXPERIMENTS}

\section{A. Multiple Regressive Analysis}

Not only estrus cycle (the time duration from estrus to the next estrus) but also the time between Delivery and the Next Estrus (DNE) is very important. DNE is defined as the time from the delivery to the next estrus. Furthermore parity (parity $\mathrm{n}$ is defined as the $\mathrm{n}$-th delivery) is also crucial factor for the 
DNE and estrus cycle other than BCS, CIDR and PG. Therefore, DNE and estrus cycle should be expressed as functions of BCS, CIDR, PG and parity. Through "multiple regressive analysis" is carried out for investigation of relations among DNE, Estrus Cycle (EC), BCS, CIDR, PG and parity $(\mathrm{P})$.

Within 30 days, 28 out of 280 cattle show their estrus cycle. Such 28 cattle are well productive. In order to obtain a reliable function, multiple regressive analysis with significant level at $5 \%$ is applied to the selected 28 cattle.

Fig. 3(a) shows influencing ratios of BCS, CIDR, PG and $\mathrm{P}$ to EC while Fig. 3(b) also shows those of BCS, CIDR, PG and $\mathrm{P}$ to DNE. The most influencing factor to EC is CIDR followed by BCS, PG, and $\mathrm{P}$ while that to DNE is CIDR followed by BCS, $\mathrm{P}$, and PG. Therefore, it is said that CIDR of hormonal treatment is very effective for EC and DNE. Also, it is said that BCS is very good indicator for EC and DNE and is easy to check. Histogram of cattle with $2.25,2.5,2.75$ and 3 of BCS is shown in Fig. 4(a) for EC while that of BCS is shown in Fig. 4(b) for DNE. From these figures, it is said that 2.5 to 2.75 of BCS cattle are very productive.

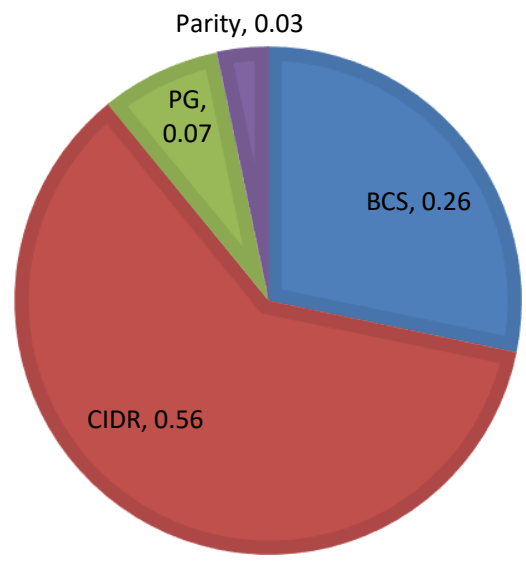

(a) EC

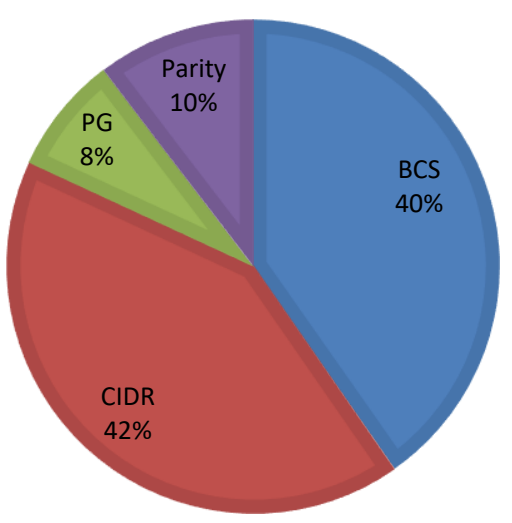

(b) DNE

Fig. 3. Influencing ratios of BCS, CIDR, $\mathrm{PG}$ and $\mathrm{P}$ to EC and DNE.

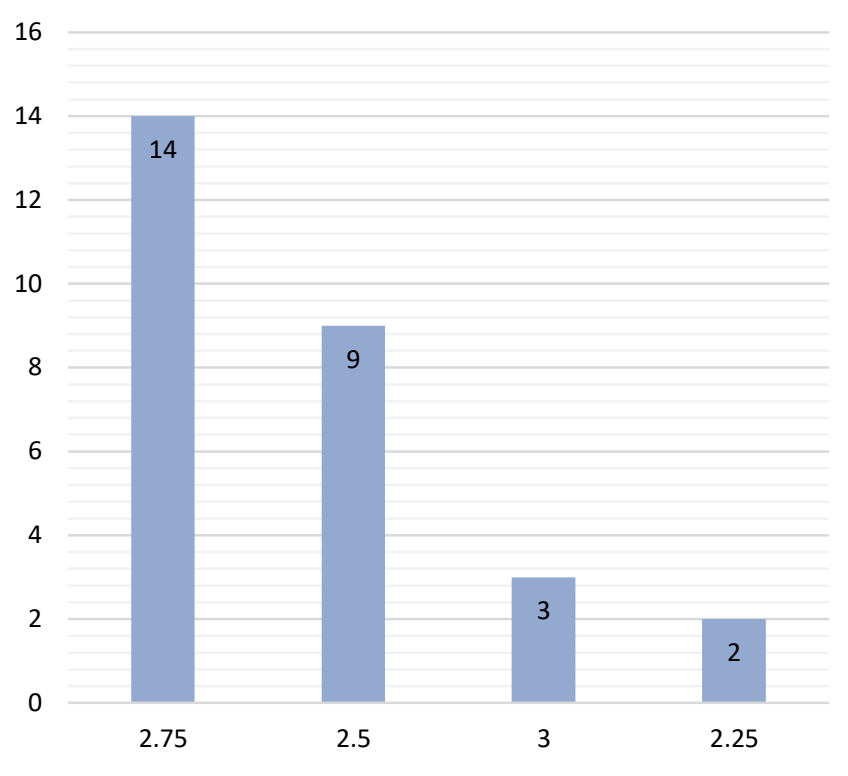

(a) EC

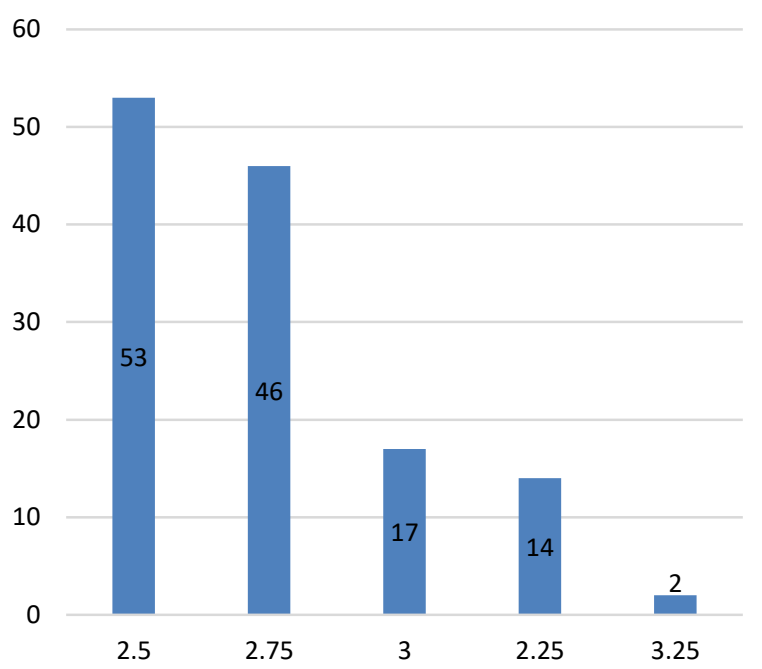

(b) DNE

Fig. 4. Histogram of cattle with 2.25, 2.5, 2.75, 3 and 3.25 of BCS for EC and DNE.

From the results from the multiple regressive analysis, EC and DNE can be expressed in (1) and (2), respectively.

$$
\begin{aligned}
& \mathrm{EC}=2.9 \mathrm{BCS}-0.05 \mathrm{P}+2.7 \mathrm{CIDR}-0.31 \mathrm{PG}+18.5 \\
& \mathrm{DNE}=18.6 \mathrm{BCS}+2.52 \mathrm{P}+21.1 \mathrm{CIDR}-3.7 \mathrm{PG}+40.62
\end{aligned}
$$

$\mathrm{F}$ value of the multiple regressive analysis is 0.942 . Therefore, the analysis is reliable enough.

\section{B. Bayesian Network}

Comparative study is conducted with Bayesian Network. Bayesian Network model or probabilistic directed acyclic graphical model is a probabilistic graphical model (a type of statistical model) that represents a set of random variables and their conditional dependencies via a directed acyclic graph (DAG). Using these BCS, CIDR, PG, P, EC is estimated based on the created Bayesian Network which is shown in 
Fig. 5(a). Also, Fig. 5(b) shows the estimated DNE with BCS, CIDR, PG, P based on Bayesian Network.

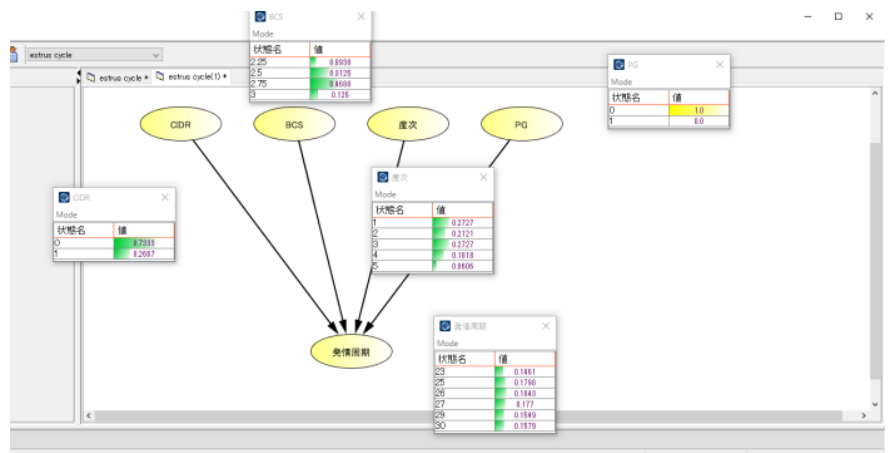

(a) EC

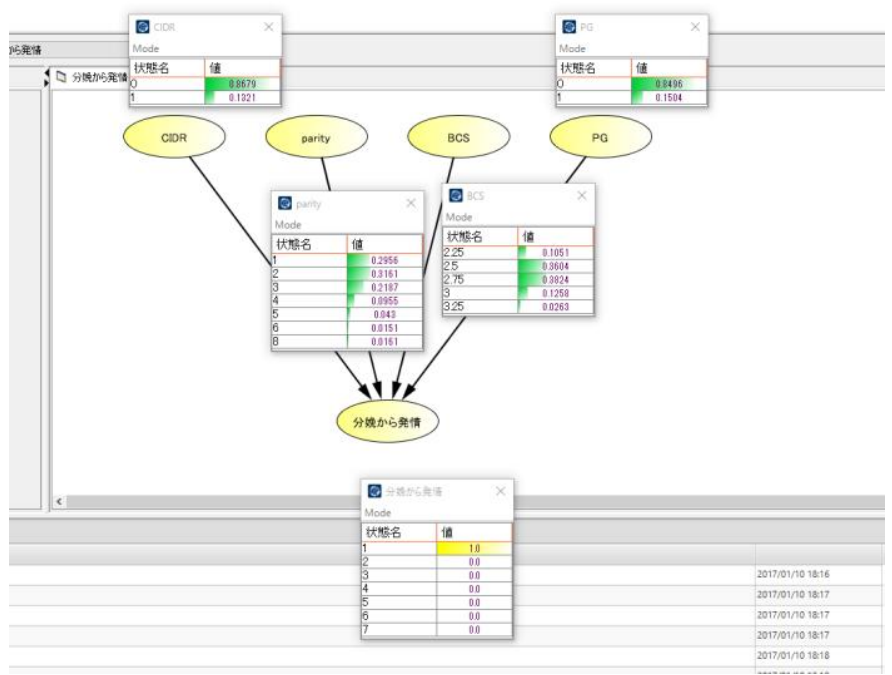

(b) DNE

Fig. 5. Analyzed result with Bayesian Network.

As the result from the analyzed result with Bayesian Network, coincident probability of EC is just $20 \%$ while that of DNE is $16 \%$. These probabilities are much less than that of multiple regressive analysis. Therefore, it is concluded that multiple regressive analysis is superior to the Bayesian Network. One of the reasons for this is relations among the influencing factors. Essentially, multiple regressive analysis may consider the relations among the influencing factors. However, Bayesian Network in this case does not take the relations into account.

\section{CONCLUSION}

Estrus cycle estimation method through correlation analysis among influencing factors based on regressive analysis is carried out for Japanese Dairy Cattle Productivity Analysis. Through the experiments with 280 Japanese anestrus Holstein dairy cows, it is found that estrus cycle can be estimated with the measured Body Condition Score: BCS, hormone treatments, parity number, based on regressive equation. Also it is found that the time from the delivery to the next estrus can be expressed with BCS, hormonal treatments, parity. Influencing factors can be clarified through multiple regressive analysis. It is said that CIDR of hormonal treatment is very effective for Estrus Cycle (EC) and the time from the Delivery to the Next Estrus (DNE). Also, it is said that BCS is very good indicator for EC and DNE and is easy to check.

Further study is required for comparison of the analysis performance of multiple regressive analysis and Bayesian network types of analysis. Also, the number of samples has to be increased for improvement of confidence level in the statistical analysis.

\section{ACKNOWLEDGEMENTS}

This research work is supported by Ministry of Agriculture, Forestry and Fisheries (MAFF), Japan under the project name of "Development of technology for enhancement of livestock lifetime productivity by improving fertility through assisted reproduction". Authors would like to thank MAFF for their support as well as the students in the $4^{\text {th }}$ research group of the Department of Information Science of the Faculty of Science and Engineering of Saga University for their valuable discussions and preparation of cattle data.

\section{REFERENCES}

[1] J. C. Whittler, "Reproductive Anatomy and Physiology of the Cow", Department of Animal Sciences. University of Missouri, Accessed December, 2015.

[2] P. D. Burns, "The Dairy Cow Heat Cycle", Colorado State University, Accessed December, 2015.

[3] J. A. Parish, J. E. Larson, and R. C. Vann, "The Estrous cycle of Cattle", Mississippi State University in cooperation with US Department of Agriculture, Publication No.2616, 2010.

[4] G. Perry, "The Bovine Estrous Cycle- FS921A", South Dakota State University-Cooperative Extensive Service USDA, Accessed December, 2015.

[5] J. Walker, and G. Perry, "Cow Condition and Reproductive Performance", Proceeding of The Range Beef Cow Symposium XX, Colorado, USA, December, 2007.

[6] L. F. M Pfeifer, S.C.B.S. Leal, A. Scheneider, E. Schemitt, and M.N. Correa, "Effect of ovulatory follicle diameter and progesterone concentration on the pregnancy rate of fixed time inseminated lactating beef cows", Revista Brasileria de Zootecnia, Vol. 41, No. 4, 2012, pp. 1004-1008.

[7] M. Matsui, and A. Miyamoto, "Evaluation of ovarian blood flow by colour Doppler Ultrasound: Practical use for reproductive management in the cow", The Veterinary Journal, 181, 2009, pp.232-240.

[8] T.A.Zacarias, S.B. Sena-Natto, A.S. Mendonca, M.M. Franco, and R.A. Figueiredo, "Ovarian Follicular Dynamics in 2 to 3 months old Nelore Calves (Bos Taurus indices)", Journal of Animal Reproduction, Vol. 12, No.2, June,2015, pp.305-311.

[9] G.A. Perry, M.F. Smith, A.J. Roberts, M.D. MacNeil, and T.W. Geary, "Relationship between size of the ovulatory follicle and pregnancy success in beef heifers", Journal of Animal Science, 85:684-689, 2007.

[10] A. Honnens, C. Voss, K. Herzog, H. Niemann, D. Rath, and H. Bollwein, "Uterine blood flow during the first 3 weeks of pregnancy in Dairy Cows" Journal of Theriogenology, Vol.70, 2008. Pp.1048-1056.

[11] G. Campanile, G. Neglia, R. Di Palo, B. Gasparrini, C. Pacelli, M. D'Occhio, and L. Zicarelli, "Relationship of body condition score and blood urea and ammonia to pregnancy in Italian Mediterranean buffaloes", Reproduction Nutrition Development, EDP Sciences, 2006, 46 (1), pp.57-62.

[12] G. A. Perry, O. L. Swanson, E. L. Larimore, B. L. Perry, G. D. Djira, and R. A. Cushman, "Relationship of follicle size and concentrations of estradiol among cows exhibiting or not exhibiting estrus during a fixedtime AI protocol", Journal of Domestic Animal Endocrinology, 48(2014), pp.15-20.

[13] W. Kellogg, "Body Condition Scoring with dairy cattle- FAS4008", University of Arkansas, USA, Accessed on: January 2016. 
[14] J.M. Bewley, and M.M. Schutz, "Review: An interdisciplinary review of Body Condition Scoring for Dairy Cattle", The Professional Animal Scientist 24(2008), pp. 507-529.

[15] F.C. Castro, J.O. Porcayo, R.J. Ake-Lopez, J.G.M. Monforte, R.C. Montes-Perez, and J.C.S. Correa, "Effect of Body Condition Score on Estrous and Ovarian function characteristics of Synchronized BeefMaster Cows", Journal of Tropical and Subtropical Agroecosystems, 16(2013), pp.193-199.

[16] K. Yamada, T. Nakao, and N. Isobe, "Effects of Body Condition Score in Cows Peripartum on the onset of the Postpartum Ovarian Cyclicity and Conception rates after Ovulation Synchronized/ Fixed-Time Artificial Insemination", Journal of Reproduction and Development, Vol. 49, No. 5, 2003, pp.381-388.

[17] M. DeJarnette, "Estrus Synchronization: A Reproductive Management Tool", White Paper, Select Sires Inc., Ohio, USA, 2004.

[18] M. Takagi, N. Yamagishi, I.H. Lee, K. Oboshi, M. Tsuno, and M.P.B. Wijayagunawardane, "Reproductive management with Ultrasound Scanner Monitoring System for a high-yielding Commercial Diary Herd Reared under Stanchion Management Style", Asian-Australian Journal of Animal Science, 2005, Vol. 18, No. 7, pp. 949-956.

[19] G.P. Adams, and J. Singh, "Bovine Bodyworks: ultrasound Imaging of Reproductive Events in Cows", WCDS Advances in Dairy Technology, Vol. 23, 2011, pp. 239-254.

[20] J.H.M. Viana, E.K.N. Arashiro, L.G.B. Siqueira, A.M. Ghetti, V.S. Areas, C.R.B. Guimaraes, M.P. Palhao, L.S.A. Camargo, and C.A.C Fernandes, "Doppler Ultrasonography as a tool for Ovarian Management", Journal of Animal Reproduction, Vol. 10, No. 3, September 2013, pp. 215-222.

[21] P.M. Fricke, and G.C. Lamb, "Practical applications of ultrasound for reproductive management of beef and diary cattle", Proceedings of The Applied Reproductive Strategies in Beef Cattle Workshop, Kansas, USA, September 2002.

[22] G.C. Lamb, C.R. Dahlen, and D.R. Brown, "Reproductive Ultrasonography for monitoring Ovarian Structure Development, Fetal Development, Embryo Survival and Twins in Beef Cows", The Professional Animal Scientist Symposium, No. 19, 2003, pp. 135-143.
[23] Anonymous, "Body Condition Scoring in Dairy Cattle- AI10782", White Paper, Elanco Animal Health, 1-800-428-4441, 2009.

[24] J.D. Ferguson, D.T. Galligan, and N. Thousen, "Principal Descriptor of Body Condition Score in Holstein Cows", Journal of Dairy Science, No.77, 1994, pp.2695-2703.

[25] Iqbal Ahmed, Kenji Endo, Osamu Fukuda, Kohei Arai,Hiroshi Okumura, Kenichi Yamashita, Japanese Dairy Cattle Productivity Analysis using Bayesian Network Model (BNM), International Journal of Advanced Computer Science and Applications, 7, 11, 31-37, 2016.

[26] Report of National Livestock Breeding Center, Japan. Website: http://www.nlbc.go.jp/en/, Accessed January, 2016.

\section{Authors PRofile}

Kohei Arai, He received BS, MS and PhD degrees in 1972, 1974 and 1982, respectively. He was with The Institute for Industrial Science and Technology of the University of Tokyo from April 1974 to December 1978 and also was with National Space Development Agency of Japan from January, 1979 to March, 1990. During from 1985 to 1987, he was with Canada Centre for Remote Sensing as a Post-Doctoral Fellow of National Science and Engineering Research Council of Canada. He moved to Saga University as a Professor in Department of Information Science on April 1990 He was a counselor for the Aeronautics and Space related to the Technology Committee of the Ministry of Science and Technology during from 1998 to 2000. He was a councilor of Saga University for 2002 and 2003. He also was an executive councilor for the Remote Sensing Society of Japan for 2003 to 2005. He is an Adjunct Professor of University of Arizona, USA since 1998. $\mathrm{He}$ also is Vice Chairman of the Commission-A of ICSU/COSPAR since 2008. He received Science and Engineering Award of the year 2014 from the minister of the ministry of Science Education of Japan and also received the Best Paper Award of the year 2012 of IJACSA from Science and Information Organization (SAI). In 2016, he also received Vikram Sarabhai Medal of ICSU/COSPAR and also received 30 awards. He wrote 37 books and published 580 journal papers as well as 370 conference papers. He is Editorin-Chief of International Journal of Advanced Computer Science and Applications as well as International Journal of Intelligent Systems and Applications. http://teagis.ip.is.saga-u.ac.jp/ 